FERREIRA, M.D.; KUMAKAWA, M.K.; ANDREUCCETTI, C.; HONÓRIO, S.L.; TAVARES, M.; MATHIAS, M.L. Avaliação de linhas de beneficiamento e padrões de classificação para tomate de mesa. Horticultura Brasileira, Brasília, v.23, n.4, p.940-944, out-dez 2005.

\title{
Avaliação de linhas de beneficiamento e padrões de classificação para tomate de mesa
}

\author{
M.D. Ferreira ${ }^{1}$; M.K. Kumakawa ${ }^{2}$; C. Andreuccetti ${ }^{1}$; S.L. Honório ${ }^{1}$; M. Tavares ${ }^{3}$; M.L. Mathias ${ }^{2}$ \\ ${ }^{1}$ UNICAMP, Fac. Eng. Agrícola, Conselho Integrado de Tecnologias de Processos, Distrito Barão Geraldo, C. Postal 6011, 13083-875 \\ Campinas-SP; E-mail: marcos.ferreira@agr.unicamp.br, ${ }^{2}$ UNICAMP, Fac. Eng. Mecânica, Campinas-SP; ${ }^{3}$ Universidade Federal de \\ Uberlândia, Fac. Matemática, Av. João Naves de Ávila, 2121, 38408-100 Uberlândia-MG.
}

\section{RESUMO}

Atualmente, existem disponíveis no mercado brasileiro alternativas quanto a equipamentos de beneficiamento e classificação para tomate de mesa, sendo os mais comuns aqueles que realizam a padronização através dos parâmetros tamanho e peso do produto. Neste trabalho realizou-se um levantamento em cinco unidades de beneficiamento e classificação para tomate de mesa, localizadas na região de Campinas (SP), caracterizando o tipo de equipamento, seu funcionamento, as etapas envolvidas no processo e aferindo a classificação utilizada pelos galpões, comparando-a com aquela determinada pelo Programa Brasileiro para a Modernização da Horticultura, desenvolvido pela Companhia de Entrepostos e Armazéns Gerais de São Paulo, Ceagesp. A classificação dos tomates foi realizada medindo-se os diâmetros transversais dos frutos por meio de um paquímetro digital. Na avaliação das linhas de beneficiamento e classificação, observou-se grande variação nas etapas do processo: quanto às dimensões, determinou-se aproximadamente $99 \%$ de diferença entre os comprimentos aferidos; quanto ao número e ao tipo de escovas, na etapa de lavagem encontrou-se o mínimo de 4 escovas e o máximo de 19 escovas nylon, na etapa de secagem o mínimo de 5 e o máximo de 15 escovas espuma (poliuretanopoliéter), e na etapa da segunda secagem, incluindo o polimento, o mínimo de 6 e o máximo de 64 escovas, preferencialmente de origem animal, crina. Observou-se ainda para os padrões de classificação maiores o não cumprimento das normas nos galpões de beneficiamento avaliados. Das 14 amostragens realizadas nas 5 unidades de beneficiamento, $57,2 \%$ enquadraram-se às normas de classificação recomendadas.

Palavras-chave: Lycopersicon esculentum Mill, escovas, galpões, normas, diâmetros de frutos.

\begin{abstract}
Evaluation of packing lines and classification standards for fresh market tomatoes in Brazil

Currently, are available in the Brazilian market some alternatives of packing and standardization equipment for fresh market tomatoes. The most common ones classify the fruits through their size and weight. Five packing line units for classifying fresh market tomatoes, located in the Campinas region, Brazil, were evaluated. The type of equipment was characterized; the involved steps in the process, and the working functions were analysed. A comparison was done between the classification recommended by the Brazilian Program for the Modernization of the Horticulture (developed by the CEAGESP), and those used in the different packing houses evalkuated. The classification was carried out measuring the transversal diameter of the fruits with a digital paquimeter. A large variation was observed (99\%) in the length of the packing lines. In the washing step the number of brushes varied from 4 to 19 nylon brushes. In the drying step, the number of foam brushes (polyurethane-polyether) ranged from 5 to 15, and from 6 to 64 brushes of animal origin (horse poil mainly) in the second drying and polishing step. For bigger classification standards a lack of fulfillment of the norms was observed. From the 14 samples taken in the 5 packing houses, only $57.2 \%$ worked accordingly to the recommended norms.
\end{abstract}

Keywords: Lycopersicon esculentum Mill, brushes, packing houses, standards.

\section{(Recebido para publicação em 15 de agosto de 2004 e aceito em 3 de agosto de 2005)}

$S^{c o s}$ gundo Cançado Jr. et al. (2003), o tomateiro é a segunda hortaliça cultivada no mundo, sendo que em quantidade produzida é superada apenas pela batata. Das 108.499.056 t métricas de produção mundial de tomate em 2002, 3.518.163 foram produzidas pelo Brasil, colocandoo como oitavo produtor mundial, correspondendo a uma área colhida de 62.291 ha. O volume comercializado na Ceagesp (SP) neste mesmo ano foi de 243.794 t, sendo o tomate salada responsável por $189.405 \mathrm{t}$, com preço médio de $\mathrm{R} \$ 0,85 / \mathrm{kg}$ baseado no volume comercializado na Ceagesp (FNP CONSULTORIA
\& AGROINFORMATIVOS, 2004). Os mesmos autores afirmaram que uma boa alternativa para aumentar a lucratividade dos produtores é otimizar a logística de produção, colheita e distribuição do tomate, o que acarretaria numa melhora de qualidade do produto e numa diminuição das perdas pós-colheita.

As perdas na pós-colheita podem ser causadas por danos mecânicos, armazenamento impróprio, manuseio excessivo, transportes inadequados e grande tempo de exposição no varejo.

Danos mecânicos devido a impactos, compressão, vibração, cortes e ra- chaduras estão relacionados com alterações fisiológicas, metabólicas, de aroma, sabor e qualidade em diversos produtos hortícolas (MORETTI et al., 1998). Danos mecânicos podem ser ocasionados por uma pequena força, por impacto com outro fruto ou em uma superfície dura, sendo cumulativos durante as práticas de manuseio pós-colheita (MOHSENIN, 1986; SARGENT et al., 1992). Portanto, as etapas de manuseio do produto, desde o campo até o consumidor, devem ser cuidadosamente coordenadas e integradas para maximizar a qualidade final do produto 
(SARGENT et al, 1992). Hyde e Zhang (1992) relatam que as escovas utilizadas em uma linha de beneficiamento e classificação possuem diferentes velocidades de acordo com a sua finalidade. Porém, a velocidade excessiva das escovas e/ou a excessiva exposição a elas, também podem causar danos aos frutos, em especial se as escovas utilizadas possuírem superfícies pontiagudas e rígidas. Uma linha de beneficiamento e classificação de frutas e hortaliças é composta por etapas como recebimento, préseleção, lavagem, secagem, classificação e embalagem (MILLER et al., 2001).

Segundo Ferreira et al. (2004), os frutos são avaliados, dentre outros parâmetros, pelo tamanho que, por sua vez, é medido através da circunferência ou diâmetro transversal. Para Belém (2003), a classificação garante um padrão único para os produtores, atacadistas e consumidores finais, promove maior facilidade na comercialização, possibilitando que os melhores agricultores possam ter seus produtos valorizados, diminuindo as perdas, além de garantir ao consumidor um elevado padrão de qualidade de frutas e hortaliças. A classificação do tomate de mesa também interfere na qualidade final, uma vez que este é suscetível a danos provocados pelo manuseio incorreto, seja da classificação manual ou da mecânica.

Produtos com características de tamanho e peso padronizados são mais fáceis de ser manuseados em grandes quantidades, pois apresentam menores perdas, produção mais rápida e melhor qualidade (CHITARRA; CHITARRA, 1990).

Objetivou-se com este trabalho caracterizar os equipamentos (nacionais e importados) de beneficiamento e classificação para tomate de mesa em cinco unidades localizadas na região de Campinas (SP), identificando as etapas envolvidas no processo e os parâmetros de funcionamento tais como material utilizado, tipo de classificadora, escovas empregadas na etapa de limpeza e lavagem. Estabeleceu-se também o relacionamento entre a classificação utilizada pelas unidades referidas com a recomendada pelo Programa Brasileiro para a Modernização da Horticultura
(CEAGESP, 2000), verificando se as normas preconizadas estavam sendo cumpridas.

\section{MATERIAL E MÉTODOS}

A caracterização dos equipamentos de beneficiamento e classificação foi realizada pela identificação dos materiais utilizados na construção do classificador, das medidas de rotação de operação das esteiras de lavagem, secagem e polimento. Dimensionou-se o tipo de máquinas beneficiadoras empregadas por meio de medidas feitas com o auxílio de uma trena profissional. Foi mensurado o tamanho de cada etapa do equipamento, aferindo-se tanto o comprimento quanto as larguras interna e externa. Na etapa de limpeza, polimento e secagem, identificaram-se a quantidade e qualidade das escovas utilizadas, classificando o material das escovas de acordo com sua origem em vegetal, animal e sintético. Para avaliação das condições das escovas foi utilizada uma escala de notas de 1 a 5, correspondente ao nível de conservação das escovas (1=escovas em péssimo estado de conservação, com ausência no número de cerdas; $2=$ estado de conservação ruim, mas sem falhas na escova; $3=$ intermediário, escovas em uso, com cerdas eretas, mas apresentando algum desgaste por uso; 4=escovas novas com pouco uso; 5=escovas recém instaladas). Foram avaliadas as escovas nas etapas referentes à lavagem, secagem e polimento. Aferiu-se a rotação de operação das escovas (rpm) nas etapas já mencionadas através da determinação de um ponto de referência, utilizando-se um cronômetro de precisão, considerando um minuto como tempo padrão. Realizaram-se cinco repetições para cada grupo de escovas, considerando-se como resultado final a média das repetições.

A eficiência do processo de classificação foi avaliada por medições do diâmetro transversal dos frutos. Verificouse sua adequação dentro das normas de padrão e classificação indicadas pelo Programa Brasileiro para a Modernização da Horticultura (CEAGESP, 2000), determinando-se a eficiência dos equipamentos utilizados nas unidades pesquisadas. A metodologia baseou-se em recomendações de Sargent et al. (1991) e Lopez Camelo et al. (2003). Amostras foram coletadas nos padrões de classe (diâmetros) 3A, 2A e 1A, conforme disponibilidade nos galpões, respectivamente equivalente às classes Grande, Médio e Pequeno (CEAGESP, 2000), denominações mais usadas após embalamento, em um número de 100 frutos para cada padrão de classificação. A análise dos resultados foi feita pelo Teste t, para um intervalo de confiança de $90 \%$. A confiabilidade de $90 \%$ para o método foi adotada segundo o limite de tolerância para mistura de tomates pertencentes a classes diferentes, que não deve ultrapassar $10 \%$ de frutos que pertençam à classe imediatamente superior e/ou inferior, conforme descreve o Programa Brasileiro para a Modernização da Horticultura (CEAGESP, 2000) e Ferreira et al. (2004).

\section{RESULTADOS E DISCUSSÃO}

As cinco unidades de beneficiamento e classificação estudadas foram nomeadas de Galpões 1 a 5, sendo que todos trabalhavam com capacidade inferior à máxima. Galpões 1, 2 e 3 eram compostos de equipamentos mistos, etapa de recebimento e limpeza (lavagem, secagem e polimento) de origem nacional, e classificação com maquinário importado. Galpões 1 e 3 utilizavam-se da classificação por diâmetro e cor; Galpão 2, classificação por peso e cor. Galpão 4 possuía linha de beneficiamento e classificação por peso importada, sendo a classificação por cor realizada manualmente. Galpão 5, beneficiamento e classificação por diâmetro em equipamento nacional através da esteira de lona. Os Galpões 1, 2 e 5 classificavam, no período da pesquisa, frutos com formato redondo e os Galpões 3 e 4, tomates oblongos (CEAGESP, 2000).

Quanto à caracterização das etapas das linhas de beneficiamento e classificação observa-se, na Tabela 1, um diferencial entre os comprimentos das etapas constituintes do equipamento de beneficiamento, bem como no comprimento total desta, que neste caso variou de $18,84 \mathrm{~m}$ a $37,49 \mathrm{~m}$. Constatou-se que somente em um galpão o recebimento 
Tabela 1. Caracterização dimensional (comprimento, m) em cinco unidades de beneficiamento e classificação para tomate de mesa. Campinas, UNICAMP, 2003.

\begin{tabular}{lccccc}
\hline \multirow{2}{*}{ Etapas } & \multicolumn{4}{c}{ Dimensões dos galpões de beneficiamento (m) } \\
\cline { 2 - 6 } & Galpão 1 & Galpão 2 & Galpão 3 & Galpão 4 & Galpão 5 \\
\hline Tanque Recebimento & $\mathrm{El}^{*}$ & $\mathrm{El}^{*}$ & $\mathrm{El}^{*}$ & 4,57 & $\mathrm{El}^{*}$ \\
Recebimento & 3,47 & 2,24 & 2 & 3,1 & 3,4 \\
Lavagem & 1,92 & 2,45 & 2,45 & 1,43 & 2,1 \\
Esteira & $\mathrm{El}$ & $\mathrm{El}^{*}$ & 1,55 & $\mathrm{El}^{*}$ & $\mathrm{El}^{*}$ \\
Secagem & 1,75 & 0,75 & 0,93 & 1,43 & 1,65 \\
Secagem 2/Polimento & 3,8 & 2,4 & 0,93 & 3,86 & 3,8 \\
Seleção & $\mathrm{El}$ & 4,8 & $\mathrm{El}^{*}$ & $\mathrm{El}^{*}$ & 2,5 \\
Saída Seleção & $\mathrm{El}$ & 2,45 & $\mathrm{El}$ & $\mathrm{El}^{*}$ & $\mathrm{El}^{*}$ \\
Etapa Alimentação & 6,28 & $\mathrm{El}$ & 1,62 & 5,7 & $\mathrm{El}^{*}$ \\
Entrada Colorimetro & $\mathrm{El}$ & 2,85 & $\mathrm{El}^{*}$ & $\mathrm{El}^{*}$ & $\mathrm{El}^{*}$ \\
Colorimetro & 1,8 & 1 & 1,7 & $\mathrm{El}^{*}$ & $\mathrm{El}^{*}$ \\
Saída Colorimetro & $\mathrm{El}$ & 1,85 & $\mathrm{El}^{*}$ & $\mathrm{El}^{*}$ & $\mathrm{El}^{*}$ \\
Linha Classificação & 6,44 & 16,7 & 9,52 & 9 & 5,39 \\
\hline Total & 25,46 & 37,49 & 20,7 & 29,09 & 18,84 \\
\hline *EI = etapa inexistente & & & & &
\end{tabular}

*EI = etapa inexistente.

Tabela 2. Classificação das escovas em cinco galpões de beneficiamento e classificação para tomates de mesa, quanto ao número e material utilizado nas etapas de lavagem, secagem e polimento. Campinas, UNICAMP, 2003.

\begin{tabular}{|c|c|c|c|c|c|c|}
\hline \multirow{3}{*}{ Galpões } & \multicolumn{6}{|c|}{ Etapas } \\
\hline & \multicolumn{2}{|c|}{ Lavagem } & \multicolumn{2}{|c|}{ Secagem } & \multicolumn{2}{|c|}{ Secagem2/Polimento } \\
\hline & $\begin{array}{c}\mathbf{N}^{\circ} \\
\text { Escovas }\end{array}$ & Material & $\begin{array}{c}\mathbf{N}^{\circ} \\
\text { Escovas }\end{array}$ & Material & $\begin{array}{c}\mathrm{N}^{\circ} \\
\text { Escovas }\end{array}$ & Material \\
\hline 1 & 15 & Nylon & 15 & Espuma & 30 & Crina \\
\hline 2 & 19 & Crina & 5 & Espuma & 64 & PVC \\
\hline 3 & 10 & Nylon & 9 & Espuma & 16 & Crina \\
\hline 4 & 4 & Nylon & 6 & Espuma & 6 & Nylon \\
\hline 5 & 16 & Nylon & 14 & Espuma & 30 & Crina \\
\hline
\end{tabular}

Tabela 3. Rotações das escovas nas diferentes etapas em cinco galpões de beneficiamento e classificação para tomate de mesa. Campinas, UNICAMP, 2003.

\begin{tabular}{lccccc}
\hline \multirow{2}{*}{ Galpões } & \multicolumn{5}{c}{ Etapas (rotação rpm) } \\
\cline { 2 - 6 } & Lavagem & Lavagem 2 & Secagem & Secagem 2 & Polimento \\
\hline 1 & 162 & $\mathrm{El}^{*}$ & 118 & $\mathrm{El}^{*}$ & 118 \\
2 & 76 & $\mathrm{El}^{*}$ & 119 & $\mathrm{El}^{*}$ & 11 \\
3 & 102 & 77 & 26 & 26 & 26 \\
4 & 46 & $\mathrm{El}^{*}$ & 46 & $\mathrm{El}^{*}$ & 46 \\
5 & 168 & $\mathrm{El}^{*}$ & 115 & 148 & 131 \\
\hline
\end{tabular}

*EI = etapa inexistente.

ocorreu em tanques de água. Importante salientar que essas diferenças de comprimento encontradas podem estar relacionadas ao tipo de classificador utilizado e ao volume diário de produção. Outro aspecto observado refere-se às dimensões da etapa de limpeza (lavagem, secagem e polimento) que diferiram entre as unidades pesquisadas. To- davia, não eram proporcionais ao comprimento máximo de cada linha, ocorrendo, portanto, equipamentos com menores dimensões totais, mas proporcionalmente com maiores dimensões nas etapas de limpeza.

O Galpão 4 apresenta o menor número de escovas nas três etapas (Tabela 2). Enquanto que na etapa de Secagem $2 /$
Polimento o Galpão 2 apresentou o maior número. Esta máquina de classificação não utilizava escovas no polimento, somente realizando secagem. Observa-se portanto uma grande diferença no número e tipos de escovas nas linhas de beneficiamento avaliadas. Miller et al. (2001) relatam que a utilização de escovas transversais para limpeza é praticamente universal para frutas e hortaliças, juntamente com a aplicação de algum detergente ou desinfetante. $\mathrm{O}$ fruto deve ser localizado imediatamente sobre o espaço entre a primeira e segunda escova, mas não sobre a escova, porque cada linha de frutas passará entre as escovas.

As escovas da maioria dos galpões estavam em condições razoáveis, nota 3 na escala proposta. Pode-se destacar os Galpões 2 e 3 por terem apresentados as escovas em melhores condições, notas 4 e 5 . A etapa de polimento apresentou escovas em melhores condições de funcionamento enquanto que as da etapa de secagem estavam em condições mais comprometedoras (nota 2). Para que o processo de limpeza seja efetivo e para o adequado funcionamento das escovas, estas devem ser continuadamente verificadas, pois ocorre desgaste por uso, com o acúmulo de impurezas, as quais prejudicam o seu apropriado funcionamento. Para tanto, revisões periódicas são recomendadas (SARDI, 2001).

Observa-se na rotação das escovas das etapas de lavagem, secagem e polimento, diferenças entre os galpões (Tabela 3). Nota-se que o Galpão 4 apresentou uma rotação baixa em todas as etapas, enquanto que os Galpões 1 e 5 se destacaram pela elevada rotação. Hyde e Zhang (1992) relatam que uma redução na velocidade das escovas reduz a intensidade das injúrias causadas pelas escovas e pela abrasão de um fruto contra o outro. Com a redução da velocidade das escovas, ocorre uma conseqüente redução no número de impactos por segundo, porém, com a redução do fluxo do produto, o impacto total pelo choque de fruta contra fruta pode continuar o mesmo. Assim, recomenda-se para cultivares de maior sensibilidade uma redução na velocidade das escovas, mas com um fluxo normal de operação dos frutos. 
Tabela 4. Resultados das classificações dadas pelos diferentes Galpões conforme formato dos tomates. Campinas, UNICAMP, 2003.

\begin{tabular}{|c|c|c|c|c|c|c|c|c|}
\hline Galpões & Formato fruto & Variável & n1 & $\begin{array}{l}\text { Média } \\
(\mathrm{mm})\end{array}$ & $\begin{array}{c}\text { Desvio } \\
\text { padrão }(\mathrm{mm})\end{array}$ & $\begin{array}{c}\text { Intervalo } \\
\text { amostra (mm) }\end{array}$ & $\begin{array}{c}\text { Intervalo } \\
\text { padrão* (mm) }\end{array}$ & Condição \\
\hline \multirow{3}{*}{1} & Redondo & $1 \mathrm{~A}$ & 100 & 59,38 & 2,96 & $58,89-59,87$ & $50-65$ & Adequado \\
\hline & Redondo & $2 \mathrm{~A}$ & 100 & 69,22 & 3,43 & $68,65-69,79$ & 65-80 & Adequado \\
\hline & Redondo & $3 \mathrm{~A}$ & 100 & 77,35 & 5,22 & $76,48-78,22$ & Acima de 80 & Inadequado \\
\hline \multirow{3}{*}{2} & Redondo & 2A Méd* & 100 & 53,17 & 2,82 & $52,71-53,64$ & $65-80$ & Inadequado \\
\hline & Redondo & $2 \mathrm{~A}$ & 100 & 56,22 & 2,48 & $55,80-56,63$ & $65-80$ & Inadequado \\
\hline & Redondo & $3 \mathrm{~A}$ & 100 & 61,67 & 4,43 & $60,94-62,41$ & Acima de 80 & Inadequado \\
\hline \multirow{2}{*}{3} & Oblongo & $1 \mathrm{~A}$ & 100 & 52,86 & 3,35 & $52,31-53,42$ & $40-50$ & Inadequado \\
\hline & Oblongo & $2 \mathrm{~A}$ & 100 & 58,52 & 3,18 & $57,99-59,05$ & $50-60$ & Adequado \\
\hline \multirow{3}{*}{4} & Oblongo & $1 \mathrm{~A}^{* *}$ (Extrinha) & 100 & 45,19 & 2,98 & $44,70-45,69$ & $40-50$ & Adequado \\
\hline & Oblongo & $1 \mathrm{~A}$ & 100 & 46,03 & 2,88 & $45,55-46,51$ & $40-50$ & Adequado \\
\hline & Oblongo & $2 \mathrm{~A}$ & 100 & 54,25 & 4,30 & $53,53-54,96$ & $50-60$ & Adequado \\
\hline \multirow{3}{*}{5} & Oblongo & $1 \mathrm{~A}$ & 100 & 58,99 & 2,58 & $58,56-59,42$ & $50-65$ & Adequado \\
\hline & Oblongo & $2 \mathrm{~A}$ & 100 & 69,57 & 3,47 & $68,99-70,15$ & $65-80$ & Adequado \\
\hline & Oblongo & $3 \mathrm{~A}$ & 100 & 76,26 & 2,95 & $75,77-76,75$ & Acima de 80 & Inadequado \\
\hline
\end{tabular}

*Esta unidade não utilizava classificação $1 \mathrm{~A}$, mas considerava esta como a de menor diâmetro.

**Unidade 4 considerava o menor diâmetro como extrinha (1A), não existindo a classificação 3A.

Quanto aos padrões de classificação, observa-se na tabela 4 os resultados referentes à verificação ou não da adequação dentro das normas para todos os galpões pesquisados. Os parâmetros indicados nas tabelas são: "Variável" (classificação adotada pelos Galpões pesquisados); "n1" (tamanho da amostra por padrão de classe); "Média" (média dos diâmetros amostrados, mm); "DP” (Desvio Padrão da amostra, mm); "Intervalo da amostra" (intervalo calculado a partir do Teste t com intervalo de confiança de 90\%, conforme metodologia); e "Intervalo padrão", intervalo de diâmetros indicados pela CEAGESP (2000) para diferentes padrões de classe.

No Galpão 1, observa-se que, para

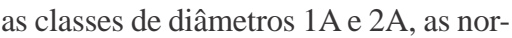
mas foram atendidas, admitindo-se tolerância de mistura de $10 \%$, conforme indica CEAGESP (2000). Ou seja, diante das análises, determinou-se que o "Intervalo da amostra" está contido no "Intervalo padrão". Para tomate 1A, dentro da amostragem de 100 frutos, 98 deles enquadravam-se nas normas de padrão e classificação da CEAGESP. Para tomate 2A, 96 frutos atenderam a classificação conforme norma. Enquanto que para os tomates classificados como 3A, 27 frutos estavam de acordo com a legislação, isto significa que o "Intervalo da amostra" não pertence ao
"Intervalo padrão", o primeiro estando abaixo do segundo. Logo, tomates que foram classificados como Grande (3A) estavam sendo supervalorizados, sendo mais adequada a classificação tamanho Médio (2A).

Todavia para Galpão 2, observa-se diferença entre a classificação dada por essa unidade de beneficiamento e a classificação indicada pela Ceagesp, para todos os níveis de classe analisados. Os intervalos das amostras não estão contidos nos intervalos padrões de classificação, sendo aqueles inferiores a esses. Neste caso, todos os tomates dessa unidade, durante a época da pesquisa, estavam sendo supervalorizados. Os tomates classificados como Médio (2A) e Grande (3A) são, conforme norma Ceagesp (2000), tomates de tamanho Pequeno, com diâmetros variando de 50 a $65 \mathrm{~mm}$.

Já no Galpão 3, o tomate classificado como 1A, está sendo desvalorizado, uma vez que o "Intervalo da amostra" está acima do "Intervalo padrão", ou seja, o adequado seria denominar o tomate como 2A (tamanho Médio) e não como 1A (Pequeno). Para a outra classe analisada (2A), determinou-se que a norma estava sendo atendida, com 71 frutos correspondendo a classificação conforme Ceagesp (2000). O "Intervalo da amostra" está contido no "Intervalo padrão".
No caso do Galpão 4, levantou-se que, para todos os níveis de classes pesquisados (1A, 1A Extrinha e 2A), as normas foram atendidas de maneira satisfatória segundo os padrões de classificação da Ceagesp (2000). Os intervalos das amostras estão contidos nos intervalos padrões indicados pela legislação. Encontraram-se 94 frutos enquadrados na norma para as classificações 1A e $1 \mathrm{~A}$ Extrinha e para tomate $2 \mathrm{~A}$, obtiveram-se 80 frutos com diâmetros de acordo com a norma.

Dentre os tomates classificados pelo Galpão 5, aqueles denominados como $1 \mathrm{~A}$ e $2 \mathrm{~A}$ encontram-se dentro das normas sugeridas pela Ceagesp (2000), com 98 e 91 frutos, respectivamente, atendendo a legislação. Já para o tomate classificado como 3A o "Intervalo da amostra" não está contido no "Intervalo padrão". O tomate, nesse caso, estava sendo supervalorizado, uma vez que deveria ter sido classificado como $2 \mathrm{~A}$ (tamanho Médio). A partir dessa análise, observa-se que o tipo de equipamento utilizado nas diferentes unidades pesquisadas, bem como sua devida calibração, afetaram os resultados de classificação para tomate de mesa.

Os resultados mostram diferenças entre os galpões para beneficiamento de tomate quanto ao equipamento utilizado, dimensões externas, número e tipo de escovas e rotações das escovas. Ob- 
serva-se através dessas informações um potencial para pesquisas futuras, com a criação de parâmetros para melhor funcionamento e eficiência nas etapas de uma linha de beneficiamento e classificação. Para a avaliação das normas de classificação, os menores padrões (frutos com menores diâmetros transversais) são coincidentes para o Padrão Ceagesp (2000), enquanto as encontradas para os maiores padrões não o são, na sua maioria, discordando dos resultados encontrados por Sargent et al. (1991). Os equipamentos que realizam classificação utilizando como padrão o diâmetro do fruto (Galpões 1, 3 e 5) atenderam em sua maioria $(62,5 \%)$ as normas preconizadas pela Ceagesp (2000). Dos $37,5 \%$ equipamentos restantes que não estavam atendendo as normas nessas unidades, $\quad 25 \%$ estavam supervalorizando e $12,5 \%$ subvalorizando o produto. Os outros dois galpões (2 e 4) classificam os frutos por peso, porém, não foi possível comparar as unidades, uma vez que em uma delas as normas não foram atendidas em nenhuma classificação realizada, enquanto que na outra unidade as classificações dos frutos se adequaram às normas.

Todas as unidades de classificação falharam em pelo menos uma classe, não atendendo os limites pré-estabelecidos e somente uma delas atingiu as normas da CEAGESP (2000) nas categorias classificadas. $\mathrm{O}$ melhor resultado obtido, nesse caso, contou com equipamento importado para a classificação através da aferição do peso dos frutos (Galpão 4). Porém, o tipo de equipamento, seja ele importado ou nacional, por si só, não é satisfatório para avaliar a eficiência das operações de classificação. Deve-se atentar para outros quesitos, de acordo com Sargent et al. (1991), tais como a calibração do equipamento (a freqüência e o rigor com que essa tarefa é realizada) e a velocidade das esteiras transportadoras. No caso do não cumprimento da norma, segundo Lopez et al. (2003), as atribuições podem ser dadas à sequiência de operações e à ve- locidade das correias de transporte. Logo, a calibração dos equipamentos deve ser feita freqüentemente, com o intuito de evitar a desvalorização ou a supervalorização do produto, rotulandose o produto de acordo com a legislação, não prejudicando os consumidores finais. Faz-se necessário a realização de treinamento dos operadores, a fim de que esses possam efetuar a adequação dos equipamentos às classificações, conforme os diferentes diâmetros e variedades existentes, comparando-se o diâmetro classificado com aquele indicado pela norma.

No caso da classificação obtida não se adequar às normas, como encontrado na maioria dos galpões estudados nessa pesquisa, Gayet et al. (1995) afirmaram que é indispensável proceder à eliminação manual dos frutos considerados fora de calibre e a sua inclusão nos lotes correspondentes. Para a garantia de um produto de qualidade é necessário que as normas estabelecidas, nesse caso para tomate de mesa, se adaptem, de acordo com Ferreira et al. (2004), à realidade agrícola com vistas as cultivares de diferentes formatos, tamanhos e cores. Por isso, é relevante a formação de recursos humanos que possam dar apoio a essa realidade, a existência de cursos e treinamentos para os trabalhadores e o compromisso dos produtores diante desses fatores.

\section{AGRADECIMENTOS}

Os autores agradecem a Fundação de Amparo a Pesquisa do Estado de São Paulo, FAPESP (O presente trabalho faz parte do Projeto UNIMAC).

\section{LITERATURA CITADA}

BELÉM, M.Q. Padronização das frutas. Revista Agroamazônica. Disponível em: <http:// www.revistaagroamazonia.com.br/12fruticultura04.htm>. Acesso em: out. 2003.

CANÇADO JÚNIOR, F.L.; CAMARGO FILHO; W.P.; ESTANISLAU, M.L.L.; PAIVA, B.M.; MAZZEI, A.R.; ALVES, H.S. Aspectos econômicos da produção e comercialização do tomate para mesa. Informe Agropecuário, Belo Horizonte, 2003, v.24, n.219, p.7-18.
CEAGESP. Programa Brasileiro para Modernização da Horticultura. Normas de Classificação do Tomate. Centro de Qualidade em Horticultura. CQH/CEAGESP. 2000. São Paulo (CQH. Documentos 26).

CHITARRA, M.I.; CHITARRA, A.B. Pós-colheita de frutos e hortaliças: fisiologia e manuseio. Lavras: ESAL/FAEPE, 1990. 320 p.

FERREIRA, S.M.R., FREITAS, R.J.S., LAZZARI, E.N. Padrão de identidade e qualidade do tomate (Lycopersicon esculentum Mill.) de mesa. Ciência Rural, Santa Maria, v.34, n.1, p.329335, 2004.

FNP Consultoria \& Agroinformativos. Anuário da Agricultura Brasileira - Agrianual 2004. São Paulo: FNP, 2003, 496 p.

GAYET, J.P.; BLEINROTH, E.W.; MATALLO, M.; GARCIA, E.E.C.; GARCIA, A.E.; ARDITO, E.F.G.; BORDIN, M.R. Tomate para exportação: procedimentos de colheita e pós-colheita. Ministério da Agricultura, do Abastecimento e da Reforma Agrária, Secretaria do Desenvolvimento Rural, Programa de Apoio à Produção e Exportação de Frutas, Hortaliças, Flores e Plantas Ornamentais. Brasília: EMBRAPA-SPI, 1995. 34 p. (Série Publicações Técnicas FRUPEX: 13).

HYDE, G.M.; ZHANG, W. Apple Bruising Research Update: Packingline Impact Evaluations. Tree Fruit Postharvest Journal, v.3, n.3, p.12-15, 1992.

LOPEZ CAMELO, A.F.; HORVITZ, S.; GOMEZ, P.A. An approach for the evaluation of efficiency of onion packinghouse operations. Horticultura Brasileira, Brasília, v.21, n.1, p.51-54, 2003.

MILLER, W.M.; WARDOWSKI, W.F.; GRIERSON, W. Packingline Machinery for Florida Citrus Packinghouses. Extension Bulletin 239. Florida Cooperative Extension Service. Institute of Food and Agricultural Sciences, University of Florida. 2001, 26 p. Disponível em: <http://edis.ifas.ufl.edu/BODY_AE184>.

MOHSENIN, N.N. Physical properties of plant and animal materials. Vol. I. New York:Gordon Beach Science Publishers, 1986, 841 p. MORETTI, C.L.; SARGENT, S.A.; HUBER, D.J.; CALBO, A.G.; PUSCHMANN, R. Chemical composition and physical properties of pericarp, locule, and placental tissues of tomatoes with internal bruising. Journal of the American Society for Horticultural Science, 1998, v.123, n.4, p.656-600. S.A.R.D.I SOUTH AUSTRALIAN RESEARCH AND DEVELOPMENT INSTITUTE, $10^{\text {th }}$ September 2001. Disponível em: <http:// www.sardi.sa.gov.au/pages/horticulture/citrus/ cit_page.htm:sectID=184\&tempID=93>.

SARGENT, S.A.; BRECHT, J.K.; TALBOT, M.T.; ZOELNER, J.J. Performance of perforatedbelt sizers as affected by size standards for fresh market tomatoes. Applied Engineering in Agriculture, v.7, n.6, p.724-728, 1991.

SARGENT, S.A.; BRECHT, J.K.; ZOELLNER, J.J. Sensitivity of tomatoes at mature-green and breaker ripeness stages to internal bruising. Journal of the American Society for Horticultural Science, v.117, n.1, p.119-123, 1992. 